\title{
EXPERIENCES WITH THE REPAIR OF THE MITRAL VALVE IN MITRAL INCOMPETENCE
}

\author{
BY \\ G. H. WOOlER, P. G. F. NIXON, V. A. GRIMSHAW, AND D. A. WATSON \\ From the General Infirmary, Leeds
}

(RECEIVED FOR PUBLICATION NOVEMBER 20, 1961)

The mitral valve comprises four structures: annulus fibrosus, cusp tissue, chordae tendineae, and papillary muscles. The annulus fibrosus is strong at the base of the aortic cusp, where it forms part of the aortic valve ring, and weak at the base of the mural cusp. From every part of the annulus cusp tissue hangs vertically downwards into the cavity of the left ventricle in the form of a short sleeve (Fig. 1). Medially and laterally the tissue is elongated, and thickened by the insertion of chordae tendineae, to form the major aortic and mural leaflets. Anteriorly and posteriorly cusp tissue exists in the form of a delicate junctional band that may contain minor leaflets (Chieche, Lees, and Thompson, 1956). In health there are no commissures (Fig. 2). In mitral stenosis division of the junctional band may cause severe regurgitation. Chordae tendineae arise from papillary muscles and fan out as they insert into the edges and ventricular surfaces of the major cusps. It is important to realize that each papillary muscle distributes chordae to both cusps in such a way that contraction of the muscle tends to approximate the cusps (Fig. 3).

When the valve is closed the atrial surfaces of the major cusps have a wide area of contact, and eversion is prevented by chordae and papillary muscles.

\section{Pathological Changes}

All, or any one, of the components of the mitral valve may be affected by rheumatism. The distribution of disease in the chordae is an important factor in determining the predominant effects of the valvular lesion. When chordae at the anterior and posterior extremes are chiefly affected, the cusps are drawn together and their fusion with the junctional tissue results in stenosis. When chordae in the central part are chiefly affected, the cusps may be prevented from approximating, and the regurgitation that ensues causes enlargement of the atrium, dilatation of the annulus, and further regurgitation, initiating the vicious circle described so well by Burchell and Edwards (1953). The annulus at the base of the aortic cusp is strong and firmly anchored to the aortic valve ring (Fig. 4) and so dilatation of the atrium enlarges the weak lateral annulus at the base of the mural cusp, which becomes correspondingly stretched and displaced downwards. Stretching may be so extreme as to split the cusp, and downward displacement causes the illusion of the aortic cusp prolapsing into the atrium. This downward displacement has been well described by Grant (1953). Building up the mural cusp with plastic sponge may make the valve competent, but we feel that such a repair is less efficient than one that shortens and elevates the cusp.

The following observations were made at operation in 38 cases. Adhesion between major cusps was present in five cases, but in only one was the long diameter of the orifice reduced to less than $2.5 \mathrm{~cm}$. Gross dilatation of the annulus without apparent disease of the cusps, chordae or papillary muscles was present in eight patients. One of these was a man, $6 \mathrm{ft}$. in height and 14 stones in weight, who had heart failure four years before surgical treatment. At operation the clenched fist could be passed through the mitral valve. Repair appears to have been successful, for he has returned to work and presents little evidence of regurgitation (Fig. 5).

Dilatation of the ring associated with disease of the cusps and chordae was the commonest finding, being present in 23 patients. Calcification involving valve ring and atrial muscle was present in six patients.

Ankylosed valves that could not be improved were encountered some four years ago in two patients without opening snaps, before the present method of selection was introduced.

\section{Selection of Patients}

When a patient is severely disabled by mitral valvular disease and has a pansystolic murmur of 
mitral regurgitation, it is necessary to diagnose the state of the aortic cusp and to determine whether the regurgitating orifice is small and severely obstructed or large and seriously incompetent.

The state of the aortic cusp is assessed from the phonocardiographic appearance of the mitral opening snap (Nixon, Wooler, and Radigan, 1959 ;

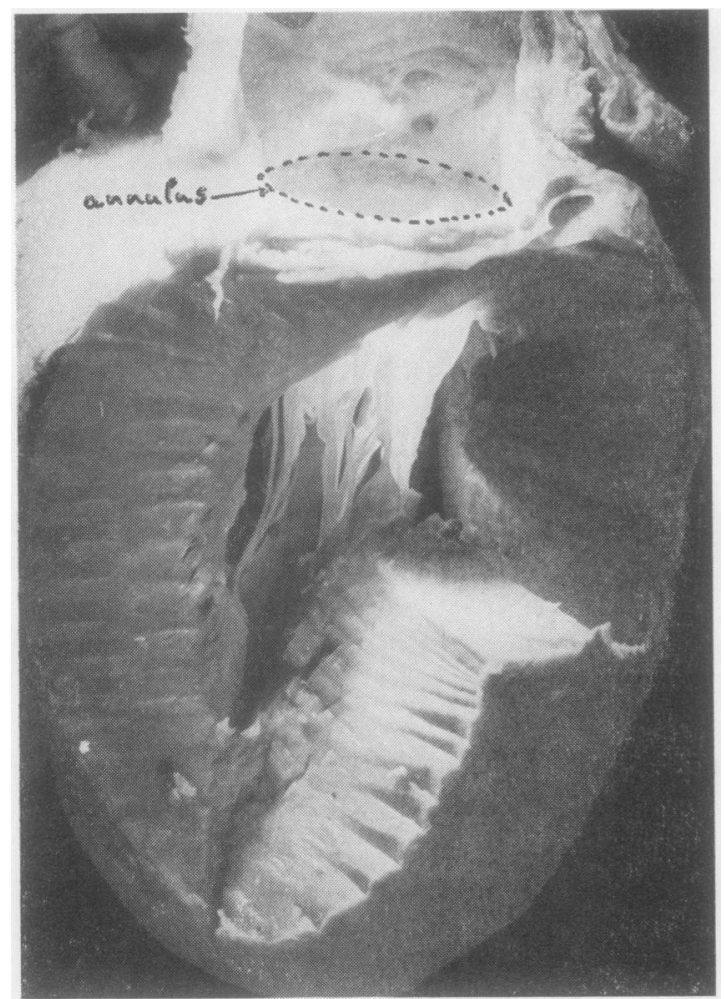

FIG. 1.- Normal mitral valve in a child's heart showing cusps hanging vertically into cavity of left ventricle and annulus lying almost in a horizontal plane.

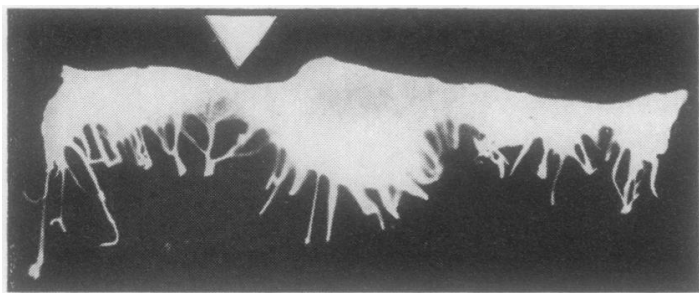

Fig. 2.-Cusp tissue has been removed from annulus fibrosus and chordae divided. Cusp tissue surrounds whole mitral orifice and there are no commissures in the normal valve. Arrow marks posterior junctional tissue at site of so-called posterior commissure.

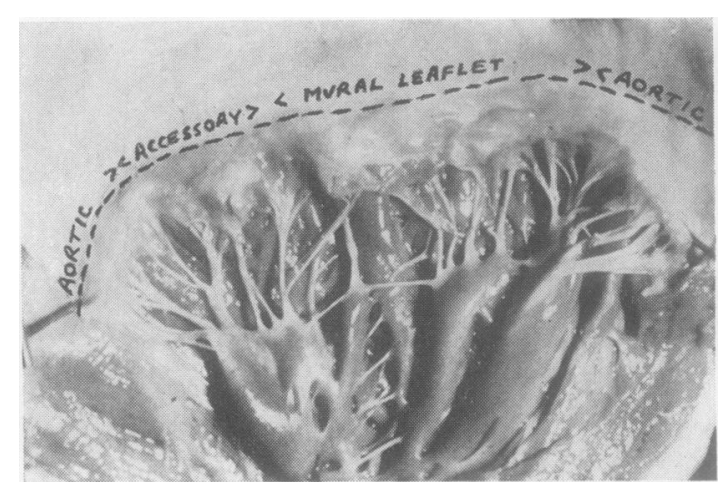

FIG. 3.- Left atrium and ventricle have been opened by an incision through aortic leaflet. Anterior and posterior papillary muscles each supply chordae for insertion into both major leaflets. Annulus is marked by a dotted line; from it arises aortic leaflet, mural leaflet, and, in this valve, a small accessory leaflet.

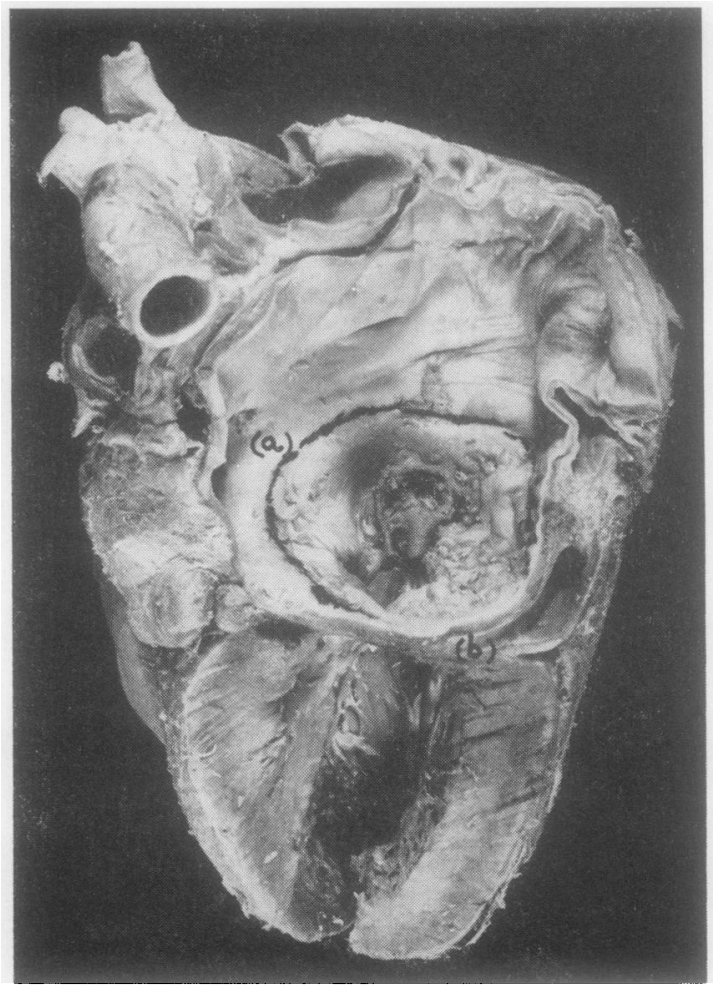

FIG. 4.-Left atrium is greatly enlarged in a case of mitral incompetence. Aortic cusp is attached to firm part of annulus at (a). Enlargement of atrium has carried mural cusp (b) down to a lower level. Aortic cusp was holed while pieces of calcium were being removed from it and had to be patched. 
1960) (Fig. 6). A mobile and pliant aortic cusp snaps open with large vibrations. A rigid and immobile cusp in an ankylosed valve gives rise to small vibrations or fails to snap.

Patients with large incompetent mitral orifices are distinguished from those with small obstructed orifices by reference to five physical signs and four investigations.

Physical Signs.-The cheeks are pink and the hands warm in about half the cases of severe incompetence whereas mitral facies and peripheral cyanosis are the rule in severe obstruction.

The arterial pulse is "jerky" and has a sharp peak in severe mitral incompetence. It may be regarded as collapsing as far as the point at which aortic valve closure ends regurgitation from the arterial system (Wood, 1954).

The apical thrust of the enlarged left ventricle is palpable in cases of incompetence free from congestive heart failure. It is not infrequently palpable in severe obstruction.

The diastolic murmur of severe mitral obstruction begins close to the opening snap and varies little in intensity as rumbles throughout diastole

FIG. 5.-Pre-operative chest radiograph. (Fig. 7). In contrast with this, the diastolic murmur of incompetence begins appreciably later

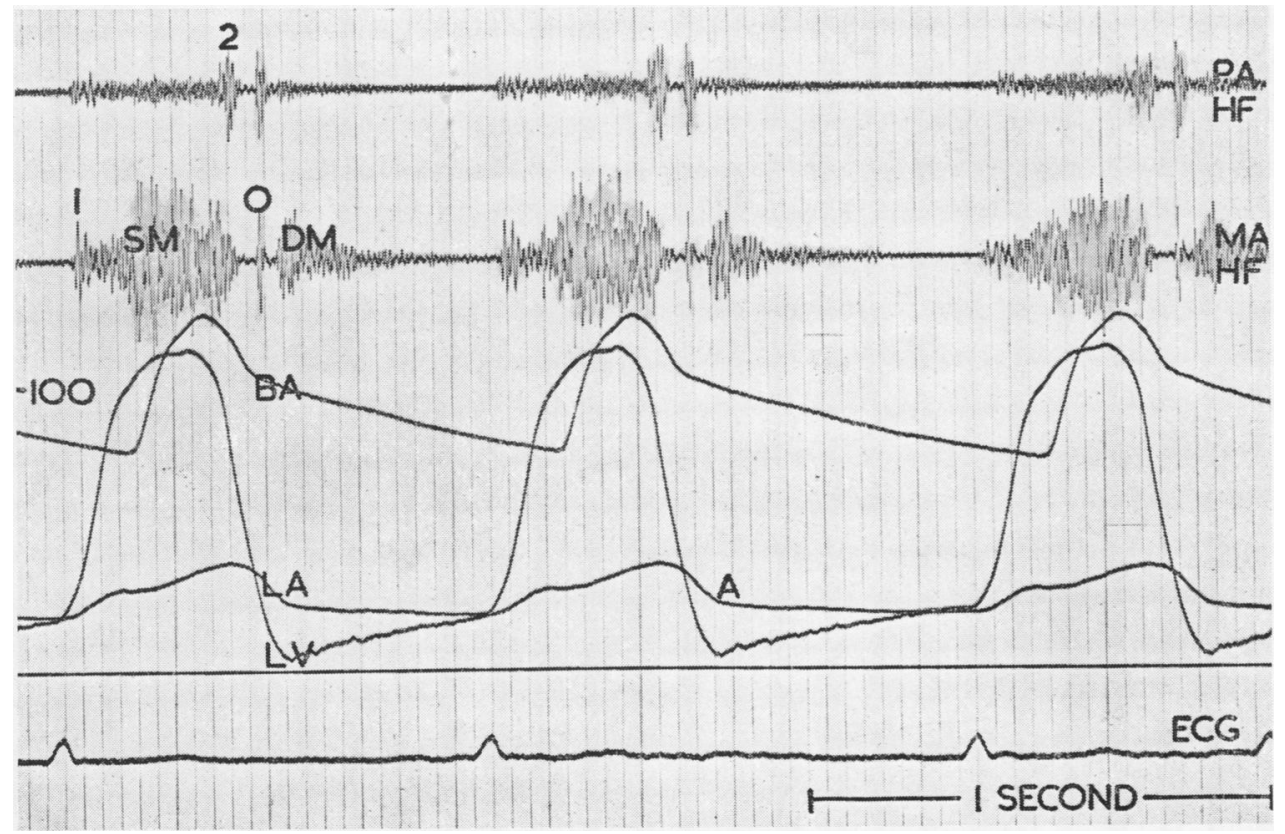

Fig. 6.-Mitral incompetence. Pulmonary (PA/HF) and mitral (MA/HF) area phonocardiograms; brachial arterial (BA), left ventricular (LV), and left atrial (LA) pressure pulses; and electrocardiogram (ECG) obtained at cardiac catheterization. There is a mitral pansystolic murmur (SM) and a loud opening snap (O). Mitral diastolic murmur (DM) begins loudly at time of left atrial annular ascent point (A), and fades away as left atrial and ventricular pressures equalize. 


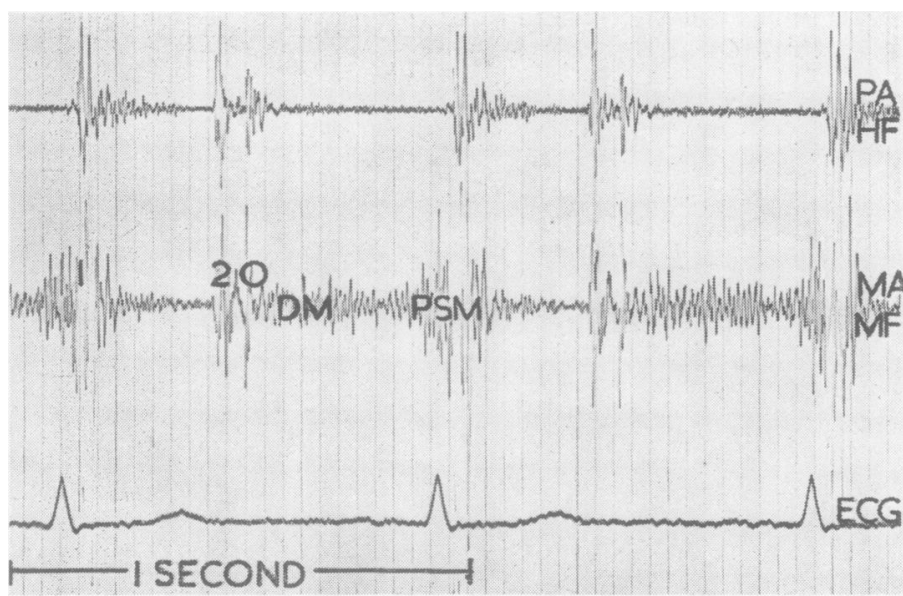

Fig. 7.- Severe mitral stenosis. Pulmonary (PA/HF) and mitral (MA/HF) phonocardiograms and electrocardiogram (ECG). Mitral diastolic murmur begins close to opening snap $(O)$ and changes little in intensity during diastole until onset of presystolic murmur (PSM).

than the opening snap at a point which corresponds with the left atrial annular ascent point and third heart sound, at the end of the rapid part of " $y$ " descent. This murmur begins loudly, sometimes with a third heart sound, and rapidly decreases in intensity as left atrial and ventricular pressures equalize in diastasis (Figs. 6 and 8) (Nixon, 1961a).

Third heart sounds occur in severe incompetence and are most obvious towards the end of expiration (Fig. 8). They do not occur in severe obstruction unless left ventricular distension is present from hypertensive, ischaemic, or aortic valvular disease (Nixon, 1961b).
Special Investigations. - The phonocardiogram distinguishes between the diastolic murmurs of stenosis and incompetence (Figs. 6, 7 , and 8 ) and records opening snaps and third heart sounds.

In incompetence the left ventricular apical impulse displacement curve (Schneider and Klunhaar, 1961) has two features not present in severe obstruction. The first is a prominent third sound wave and the second is a cessation of outward movement in the period of diastasis (Fig. 8).

Severe incompetence cannot reliably be distinguished from severe obstruction by reference to the left atrial pressure pulse " $x$ " descent, " $v$ " wave, or " $y$ " descent. The reliable sign of a mitral orifice large enough for speedy left ventricular filling is the presence of a stasis wave (Fig. 9) (Nixon and Wooler, 1961).

Ear-piece indicator-dilution curves may be readily obtained at transeptal left heart catheterization by injecting blue dye into the left atrium. When the left atrium is greatly enlarged the curve is severely distorted whatever the nature of the mitral valvular lesion. When the area of the left atrial shadow measures less than $100 \mathrm{~cm}^{2}$ on a six-foot penetrated postero-anterior chest radiograph, the dilution curve has diagnostic value. In obstruction the dip between primary and recirculation peaks is well preserved. In incompetence
Fig. 8.-Mitral incompetence. Mitral area (MA'HF) phonocardiogram; left ventricular apical displacement curve (ADC) and electrocardiogram. Phonocardiogram shows pansystolic murmur (SM). loud opening snap (O), third heart sound (3). Diastolic murmur begins loudly at time of third heart sound. Displacement curve shows third heart sound wave (3W), and flattening at end of long diastolic period indicates stasis (STASIS) in period of diastasis.

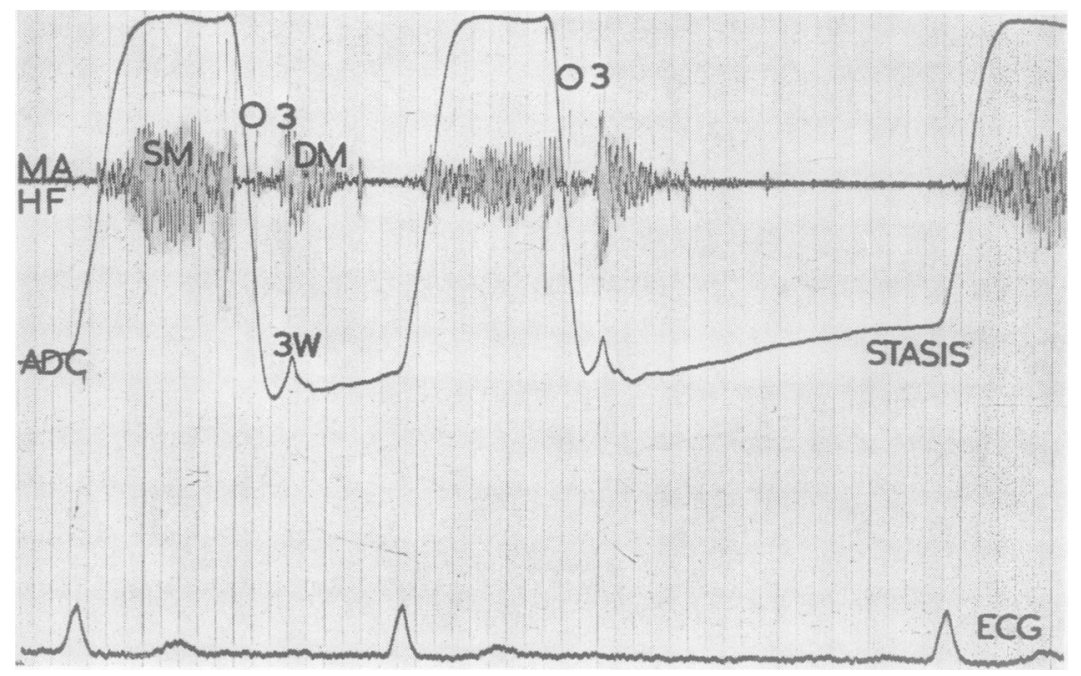




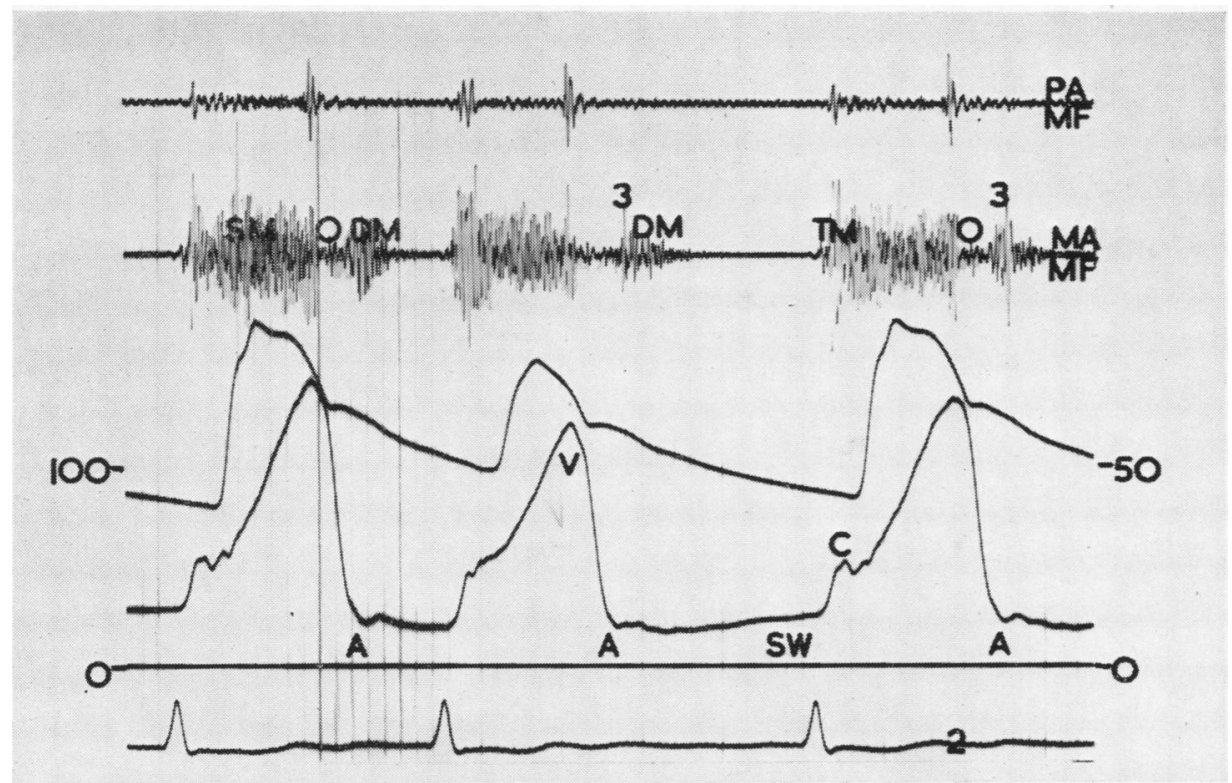

FIG. 9.-Mitral incompetence. Pulmonary (PA/MF) and mitral (MA/MF) phonocardiograms; brachial arterial and left atrial pressure pulses, and jelectrocardiogram (2). Mitral phonocardiogram shows pansystolic murmur (SM), opening snap (O), third sound (3) and characteristic diastolic murmur of incompetence (DM). Left atrial pulse shows " $c$ " and " $v$ " waves (C, V), annular ascent points (A), and stasis wave (SW), indicating completion of ventricular filling in period/of diastasis.
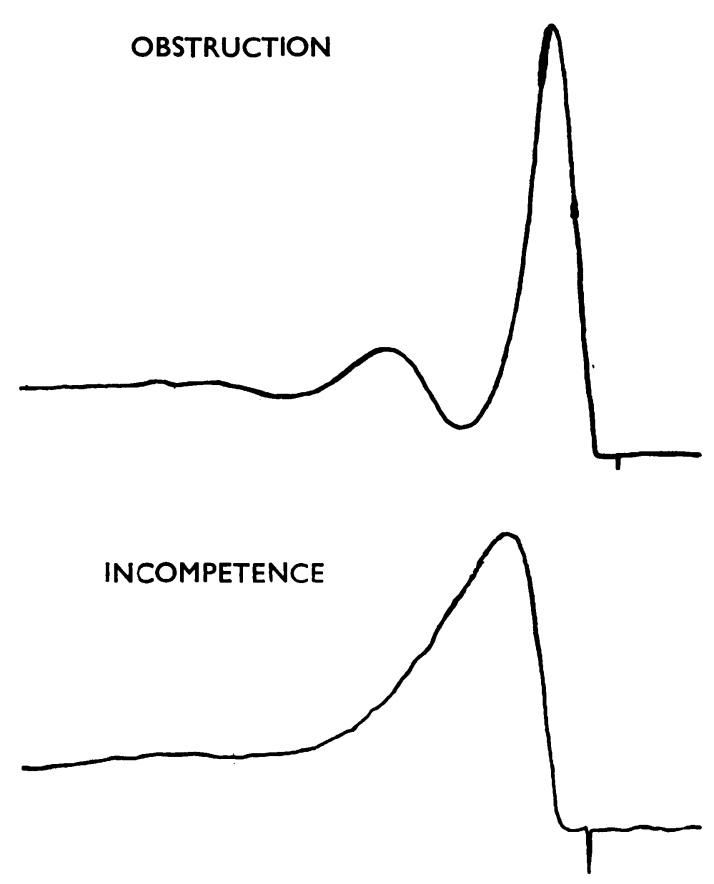

FIG. 10.-Ear-piece indicator-dilution curves. Upper tracing-severe mitral obstruction. Lower tracing-severe mitral incompetence. In neither case did left atrial area measure more than $100 \mathrm{~cm} .^{2}$ on a six-foot penetrated chest radiograph. the dip is absent or small (Fig. 10). The loss of dip results chiefly from the increased heart volumes and decreased cardiac output of severe incompetence (Nixon and Snow, 1962).

The choice of optimum time for surgical treatment calls for knowledge of the natural history of mitral incompetence and of the reactions of patients to prolonged operations. Patients with mitral incompetence appear rapidly to deteriorate after the onset of severe breathlessness, orthopnoea, and diuretic life, and soon reach a stage at which hepatic, pulmonary, renal, and metabolic changes preclude operation. Where cardiac cirrhosis is manifest, operation is likely to be followed by death from hepatic failure and bleeding. Severe lung disorder is revealed by the patient's failing to maintain normal arterial oxygen saturation when asleep from sedation with nembutal gr. 2-3 and omnopon gr. 1/6-1/3. Metabolic alkalosis, anuria, and azotaemia are likely to cause death in patients whose renal function and ability to maintain acid-base equilibrium are impaired. It is our practice to forbid oral diuretics for six months before operation, to give potassium by mouth during the month before perfusion, and to refuse operation if mersalyl injection does not cause diuresis.

Assessment of Surgical Treatment.Effective treatment of mitral incompetence must 
improve cardiac output and heart volume and relieve the left ventricle from overloading. The indicator-dilution curve and measurement of left ventricular end-diastolic pressure are likely to prove the most satisfactory methods of investigating the result of operation.

\section{ANAESTHESIA}

For premedication the digitalized patient is given pentobarbitone $100 \mathrm{mg}$. two hours before operation, and omnopon $20 \mathrm{mg}$. with papaveretum $0.4 \mathrm{mg}$. one hour beforehand. For induction a minimal dose of thiopentone $(100-150 \mathrm{mg}$.) is used. After curarization (tubocurarine $0.5 \mathrm{mg}$./ kg.) the trachea is intubated and a temperaturerecording probe is passed down the oesophagus into the post-cardiac region. From this time anaesthesia is maintained with nitrous oxide and oxygen using intermittent positive-pressure with a "pulmoflator," and tubocurarine and pethidine are given as required.

The patient is positioned for right antero-lateral thoracotomy, and electrocardiographic and electroencephalographic electrodes are applied. An intravenous drip is set up in the left arm, the left radial artery is cannulated, and catheters are passed to the superior and inferior venae cavae from the right arm and the long saphenous veins.

Before perfusion commences, tubocurarine and pethidine are added to the blood in the heart-lung machine. During perfusion the lungs are inflated to a constant pressure of $10 \mathrm{~mm}$. $\mathbf{H g}$ with helium $80 \%$ and oxygen $20 \%$. After perfusion ventilation with oxygen is recommenced; nitrous oxide is added as needed to maintain anaesthesia ; atropine $0.6 \mathrm{mg}$. followed by prostigmin $2.5 \mathrm{mg}$. are given to remove any residual curarization.

\section{PERfusion}

A modified Melrose-N.E.P. heart-lung machine is used to give a flow of 2.4 litres per square metre of body surface. The blood flows by gravity through a single $\frac{1}{2}$-in. cannula in the right atrium to the machine and is returned to the external iliac artery. The superior and inferior vena caval pressures, arterial pressure, electroencephalogram and electrocardiogram tracings are continuously recorded. At the onset of perfusion the oesophageal temperature is about $35^{\circ} \mathrm{C}$. A heat exchange unit in the extracorporeal circulation cools the patient until the ventricles fibrillate, and this usually occurs at $23-26^{\circ}$ C. The temperature at which fibrillation occurs is maintained until the mitral valve is repaired, and then the patient is rewarmed to $36^{\circ} \mathrm{C}$. The heart is defibrillated, and perfusion is stopped when good left ventricular function returns and when the blood volume appears to be satisfactory. The sign of good ventricular function is the appearance of strong ejection arterial pressure pulses with low left atrial pressure. The blood volume is assessed from the level of central venous and arterial pressure.

Heparin is neutralized with a dose of protamine sulphate determined by titration. Digoxin, 0.5$0.75 \mathrm{mg}$., is given in the 12 hours after perfusion.

\section{Operative Details}

A right thoracotomy incision is made and the pleural cavity is opened through the bed of the sixth rib. The upper margin of the sixth costal cartilage is followed to its junction with the sternum, and the internal mammary vessels are divided. Sometimes the fifth costal cartilage is divided near its sternal attachment because one needs a considerable amount of room at the front of this incision.

The pericardium is opened by a large flap which, when it is hinged back, helps to keep the lung out of the way. The right external iliac artery is cannulated and a single large tube is inserted into the right atrium for venous drainage.

At the start of perfusion a left heart vent tube is inserted into the left atrium, between and in front of the left pulmonary veins, in anticipation of left ventricular distension from aortic regurgitation. This aortic reflux must be returned to the machine, for it may amount to more than 1 litre per minute. The aortic regurgitation is not present before perfusion, and it is not caused by instrumental distortion of the aortic valve. Its onset coincides with emptying of the left ventricle; perhaps the aortic valve fails to close properly in mitral incompetence when the left ventricle ceases to eject.

To prevent air embolism, ventricular fibrillation is induced before the auricle is opened. We prefer to fibrillate the heart by hypothermia because we fear the anoxic myocardial injury that results from cross-clamping the aorta. Fibrillation usually occurs at $23-26^{\circ} \mathrm{C}$. After its onset the left atrium is opened widely. The atrial and ventricular cavities are cleared of blood and the mitral valve inspected. It is unusual to see blood clot in the auricular appendage, but if it is present it is removed. If the valve is calcified, as much calcium as possible is excised without holing the leaflets.

Adhesions fusing chordae or binding them to cusp tissue are separated with scissors, and chordae 


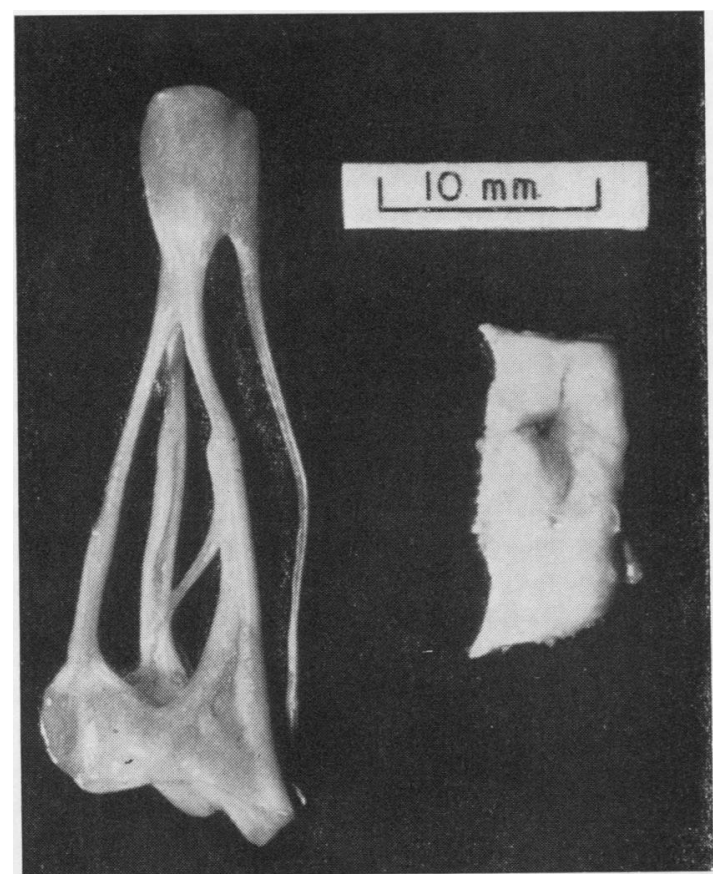

FIG. 11.-Left: normal chordae tendineae arising above from papillary muscle, dividing into separate chordae and being inserted below into cusp tissue. Right: a comparable group of chordae matted together and contracted by disease. This mass of diseased chordae was excised from papillary muscle to its insertion with cusp tissue, and demonstrates the shortening and thickening caused by rheumatism.

grossly deformed by thickening and shortening are excised without risk of the cusps everting (Fig. 11). Efficient treatment of the chordae greatly increases cusp mobility and enlarges the mitral orifice. It is the most time-consuming and important part of the repair.

Downward displacement and stretching of the mural cusp is evident once the chordae and cusps have been mobilized. It must be treated by elevation and plication, which is achieved largely by the insertion of anterior and posterior mattress sutures (Fig. 12). When these are correctly placed there is clearly no need to build up the central portion of the mural cusp with plastic material. Further elevation may be brought about by plication of the atrial wall (Fig. 13). Sometimes these mattress sutures are buried by a continuous suture which anteriorly closes the lumen of the appendage. This leaves a smooth surface in the cavity of the left atrium and adds strength to the repair (Fig. 13, lower diagram).

When the repair is finished, air is removed from the left ventricle and left atrium by allowing them to fill with blood from the aorta. For blood to fill the atrium it is necessary to pass a piece of corrugated rubber and a left heart vent catheter through the now competent mitral valve. The auricular incision is closed around these tubes while the patient is being rewarmed.

At $33-35^{\circ} \mathrm{C}$. the heart is defibrillated. In two cases with dense pericardial adhesions it was necessary to place one electrode in the left atrial cavity. Since abandoning potassium arrest defibrillation has been accomplished easily and followed by good ventricular contractions. After defibrillation the corrugated rubber drain is removed, and the left heart vent catheter is withdrawn from ventricle to atrium where it remains until the end of perfusion. There is no difficulty in weaning these patients off the pump,

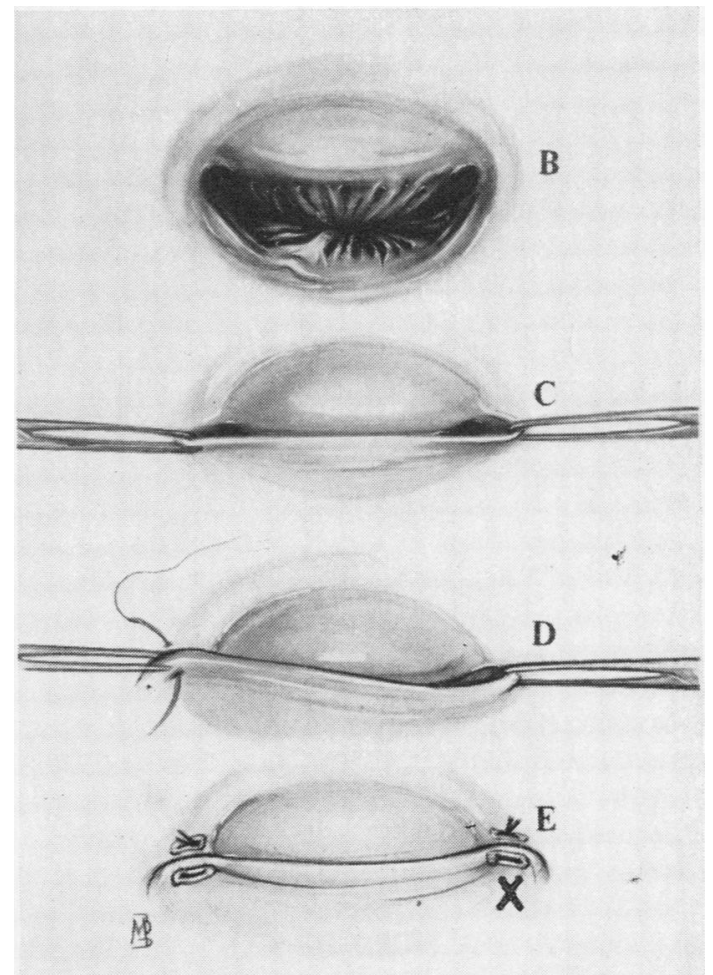

FIG. 12.-B shows downward displacement and elongation of mural cusp. A thickened and shortened chorda tendinea is seen inserted near central portion of mural cusp, deforming it and hindering mobility. C illustrates first step in repairing annulus. Tissue forceps are applied to each end of valve to elevate and shorten mura! cusp. This prevents cusp from sagging in centre. D shows first mattress suture being inserted anteriorly. Sometimes only one half of mattress suture passes through annulus, as is seen here; other half goes through auricular muscle. E shows two main mattress sutures reinforced with Tefion felt. Stitch marked $X$ lies at posterior part of valve and corresponds to stitch $X$ in Fig. 13. 


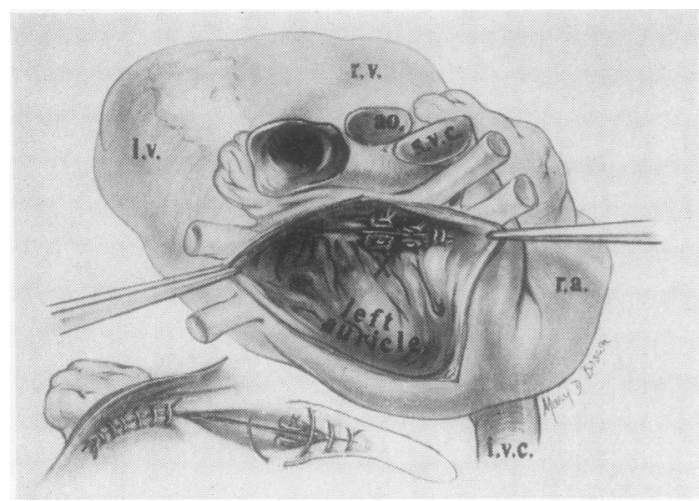

FIG. 13.-Repair of posterior part of valve. Stitch $X$ corresponds to stitch $X$ in Fig. 12 and is most important. Other mattress sutures pass only through auricular mussle. (Below) Mattress sutures may be covered by a continuous stitch passing through auricular wall. Diagram is of anterior part of valve and shows how lumen of auricular appendage is also closed.

since the left ventricle behaves extremely well, ejecting without distension or great elevation of left atrial pressure. Its great efficiency casts some doubt on the theory of myocardial weakness in mitral incompetence.

\section{Post-operative Management}

The patient is nursed in an oxygen tent for 12 hours post-operatively. To avoid the risk of pulmonary oedema, it is desirable to raise the patient to an angle of $45^{\circ}$ within a few hours of the operation. This may be done without causing hypotension if the blood volume has been well corrected (Fig. 14). To correct blood volume, sufficient blood is transfused to keep the hands pink and warm and to prevent "guttering" of the veins of the feet. To guard against excessive transfusion, the central venous pressure is measured from time to time with a saline manometer. We ceased to weigh patients and estimate blood loss during perfusion about two years ago, because we considered the results misleading.

During the first 48 hours the heart has usually behaved well and the complications we have experienced have been of a respiratory nature, sometimes causing carbon dioxide narcosis. Ten patients had tracheotomies performed and six of these required controlled respiration.

Other patients have developed hypotension and oliguria on about the third post-operative day. In three patients the oliguria progressed to anuria, and treatment on the artificial kidney was required.
Low serum potassium levels have been recorded in those patients who have previously been receiving oral diuretics.

After four and a half years' experience with open repair of the mitral valve we think we have developed a satisfactory technique in well-selected cases. Out of a total of 38 patients we have 21 alive to-day from periods varying up to four and a half years after their operation. This series includes an early period in the development of perfusion techniques. Twenty-five of our patients were in heart failure at the time of their operation. Some were brought to the operating theatre in a sitting position because they could not lie down ; others had been in bed for periods up to seven years. The patient surviving longest was operated upon four and a half years ago and she remains reasonably well to-day. During the past few months, Dr. Mary Catterall has been performing pulmonary function studies pre-operatively on all

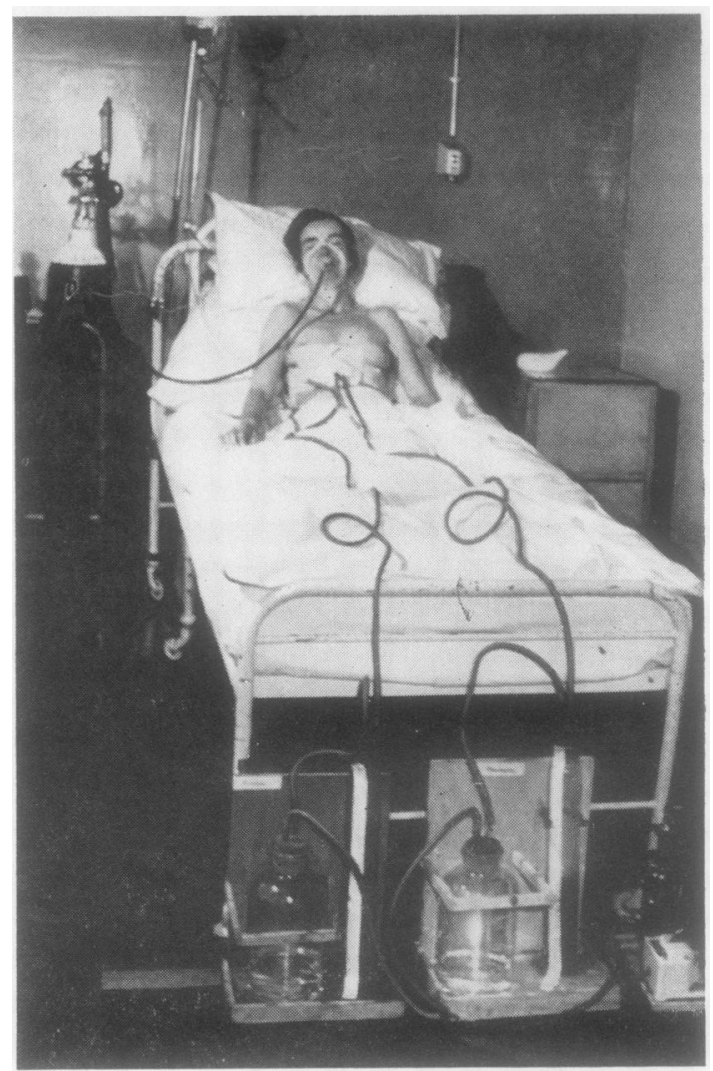

Fig. 14.-Twelve hours after operation. Head of bed is on blocks and patient is well propped up with pillows. Oxygen is being administered through an M.C. mask. 
cases of mitral incompetence. Since then we have operated only on those with reasonably good lungs and, of the last 12 patients, three have died postoperatively.

\section{SUMMARY}

This paper describes briefly the anatomy of the mitral valve and the findings at operation in 38 patients disabled from mitral incompetence, together with the method of selection and the technique of repair.

Our thanks are due to the nursing staff in our wards and theatre, and to our technicians, all of whom carry as much responsibility as ourselves.

Open cardiac surgery has been developed in Leeds largely due to the generosity of the Nuffield Founda- tion, the Medical Research Council, the Endowment Fund of the Infirmary, and other private sources, without whose financial support this work would not have been possible.

\section{REFERENCES}

Burchell, H. B., and Edwards, J. E. (1953). Circulation, 7, 747. Chieche, M. A., Lees, W. M., and Thompson, R. (1956). J. thorac. Surg., 32, 378.

Grant, R. P. (1953). Amer. Heart J., 46, 405.

Nixon, P. G. F. (1961a). Brit. Heart J., 23, 462.

- (1961b). Ibid., 23, 677.

- and Snow, H. M. Accepted for publication by Brit. Heart J. and Wooler, G. H. (1961). Brit. Heart J., 23, 161. and Radigan, L. R. (1959). Circulation, 19, 839. (1960). Brit. Heart J., 22, 395.

Schneider, H., and Klunhaar, E. W. J. M. (1961). Amer. Heart J., 61,670 .

Wood, P. (1954). Brit. med. J., 1, 1051. 